\title{
PROGRAM PEMBINAAN PEMBEBASAN BERSYARAT DI LEMBAGA PEMASYARAKATAN (STUDI KASUS DI LAPAS PEMUDA KELAS IIA TANGERANG)
}

\author{
Abdul Halim Mujtahid, \\ Politeknik Ilmu Pemasyarakatan \\ Jl. Raya Gandul No.4, RT.5/RW.6, Gandul, Cinere, Kota Depok, Jawa Barat 16514 \\ avogadro930@gmail.com
}

\begin{abstract}
Abstrak
Pembebasan Bersyarat (PB) merupakan salah satu Program Pembinaan dan juga hak bagi narapidana yang telah diatur dalam Undang-Undang. Tetapi masih terjadi beberapa permasalahan dalam pemberian $P B$ seperti rendahnya pengetahuan narapidana tentang program PB. Penelitian ini dilakukan dengan tujuan menggambarkan kondisi pelayanan Pembebasan Bersyarat yang kurang optimal dikarena banyaknya narapidana yang kurang memahami syarat, ketentuan dan mekanisme pengajuan untuk mendapatkan Pembebasan Bersyarat (PB). Penelitian terhadap pemberian PB ini dilakukan dengan menggunakan metode deskriptif kualitatif. Hasil penelitian ini berupa analisis mengapa pemberian PB ini bisa mengalami kendala dalam pemberian PB. Penelitian ini diharapkan dapat menjadi bahan evaluasi dalam pemberian $P B$ terhadap narapidana sehingga narapidana mengetahui syarat, ketentuan, dan mekanisme pengajuan $P B$.
\end{abstract}

Kata kunci: pembebasan bersyarat, narapidana, lembaga pemasyarakatan

\begin{abstract}
Conditional Exemption $(P B)$ is one of the Guidance Programs and also the rights of inmates set out in the Act. However, some problems in PB implementation such as low knowledge about PB programs. This research was conducted to review the conditions of the less optimal conditional exemption service obtained from the number that did not meet the requirements, conditions, and conditions for submission to obtain parole. Research on the provision of $P B$ was conducted using qualitative descriptive methods. The results of this study include an analysis of $P B$ that can be improved in $P B$. This research is expected to be an evaluation in the provision of $P B$ to prisoners so that prisoners' requirements, provisions, and $P B$ submissions.
\end{abstract}

Keywords: parole, prisoners, penitentiary

\section{PENDAHULUAN}

\subsection{Latar Belakang Masalah}

Pembebasan Bersyarat

merupakan program pembinaan yang telah diatur didalam Peraturan Pemerintah RI Nomor 31 Tahun 1999 Tentang Pembinaan dan Pembimbingan Warga Binaan Pemasyarakatan (WBP), program pembinaan ini memiliki output yang dimana narapidana dapat kembali kedalam kehidupan masyarakat apabila telah memenuhi syarat dan ketentuan yang berlaku, PB diberikan kepada narapidana yang telah menjalani masa pidananya sekurang-kurangnya $2 / 3$ masa pidananya dan tidak kurang dari 9 bulan masa pidana, tujuan lain dari PB yaitu salah satu program pembinaan luar lembaga guna mempersiapkan narapidana untuk dapat beradaptasi dengan lingkungan masyarakat dengan kata lain memberikan perlakuan yang sama seperti masyarakat pada umumnya tanpa adanya diskriminasi. Arti dari WBP merupakan narapidana, anak didik, dan klien pemasyarakatan. 
Dalam menjalani masa pidananya, WBP akan merasakan yang namanya kehilangan kebebasan bergerak yang telah diungkapkan oleh Dr. Sahardjo dalam 10 Prinsip Pemasyarakatan, selain dari itu Warga Binaan Pemasyarakatan masih mendapatkan hak lain yang telah ditetapkan dalam Undang-Undang Nomor 12 Tahun 1995 Tentang Pemasyarakatan salah satu contohnya narapidana berhak mendapatkan Pembebasan Bersyarat (PB) (UU Nomor 12 Tahun 1995, n.d.).
Dan dijelaskan lagi dalam pasal 15 ayat (1) KUHP yang dimana apabila terpidana telah menjalani $2 / 3$ masa pidanaya dan sekurang-kurangnya harus 9 bulan, maka mereka berhak untuk mendapatkan PB dengan syarat lain yang harus dipenuhi (KUHP, 2013). Program pembinaan di Lembaga Pemasyarakatan khususnya pemberian PB bagi WBP mengalami macam-macam gangguan dan hambatan salah satunya dikarenakan jumlah penghuni melebihi kapasitas yang ada di Lapas maupun Rutan.

Tabel 1.1 Peningkatan Jumlah Tahanan dan Narapidana pada Rutan dan Lapas Nasional Tahun 2016-2020.

\begin{tabular}{|c|c|c|c|c|c|c|}
\hline No & Tahun & Tahanan & Narapidana & $\begin{array}{c}\text { Jumlah Total } \\
\text { Penghuni }\end{array}$ & Kapasitas Hunian & $\begin{array}{c}\text { Persentasi Over } \\
\text { Croding }\end{array}$ \\
\hline 1 & 2016 & 57.532 & 123.784 & 181.316 & 132.531 & $37 \%$ \\
\hline 2 & 2017 & 65.846 & 144.422 & 210.268 & 132.531 & $59 \%$ \\
\hline 3 & 2018 & 69.816 & 166.829 & 236.645 & 132.531 & $75 \%$ \\
\hline 4 & 2019 & 70.351 & 188.569 & 258.920 & 132.531 & $95 \%$ \\
\hline 5 & 2020 & 65.252 & 204.629 & 269881 & 132.531 & $104 \%$ \\
\hline
\end{tabular}

Sumber: Sistem Database Pemasyarakatan (SDP), Direktorat Jenderal Pemasyarakatan, Kementrian Hukum dan HAM, 2020

Dapat kita lihat tabel diatas, jumlah narapidana dan juga tahanan di seluruh Unit Pelaksana Teknik (UPT) yang berada di Indonesia memiliki jumlah penghuni melebihi kapasitas yang ada, jika diperhatikan lagi jumlah narapidana dan tahanan setiap tahunnya bertambah secara signifikan, meskipun sudah ada upaya untuk mengurangi kelebihan kapasitas dengan cara pembuatan Lapas maupun Rutan yang dilakukan pemerintah melalui Ditjen Pemasyarakatan. Kelebihan kapasitas merupakan faktor utama penghambat program pembinaan yang ada di Lapas dan Rutan.

Lembaga Pemasyarakatan (LAPAS), Sahardjo mengatakan didalam pidatonya untuk pertama kalinya mengungkapkan atau menyampaikan tentang rumusan atau tujuan dari pidana penjara, yang dimana WBP tidak hanya merasakan penderitaan kehilangan kebebasan bergerak, juga pemasyarakatan bertugas untuk mendidik dan membimbing WBP agar berguna bagi bangsa dan negara(Rukmana, 2015).

Lapas Pemuda Kelas IIA Tangerang merupakan salah satu unit pelaksana teknis yang memiliki tugas dan fungsi yaitu menjalankan pembinaan bagi warga binaan pemasyarakatan. Menurut data di Lapas Pemuda Kelas IIA Tangerang pada bulan februari tahun 2020 jumlah narapidana dan tahanan yang menghuni Lapas yaitu 2940, sementara kapasitas hunian yaitu 1251. Maka dari itu Lapas Pemuda Kelas IIA Tangerang sudah melebihi kapasitas sekitar 135\%, hal ini berpengaruh besar bagi program pembinaan bagi warga binaan pemasyarakatan.

\subsection{Rumusan Masalah}


Berdasarkan Penejelasan diatas, maka penulis ingin mengkaji beberapa permasalahan, yakni:

1. Bagaimana pelaksanaan pemberian pemberian PB kepada Warga Binaan Pemasyarakatan di Lembaga Pemasyarakatan?

2. Apa saja kendala-kendala yang dihadapi dalam pemberian PB bagi warga binaan pemasyarakatan di Lembaga Pemasyarakatan?

\subsection{Tujuan Penulisan}

Dalam penulisan artikel ini, penulis ingin mengetahui mengapa warga binaan pemasyrakatan tidak mengetahui syarat, ketentuan dan mekanisme pangajuan PB. Dan faktor-faktor apa saja yang menjadi kendala dalam pemberian PB.

\section{METODE}

Penelitian ini menggunakan pendekatan deskriptif kualitatif, yang dimana merupakan strategi dalam pengumpulan data dan memanfaatkan semua data informasi terkait permasalahan yang ada (Cresswell, 2016). Penelitian ini bertujuan untuk mengetahui bagaimana pelaksanaan pemberian $\mathrm{PB}$ dan kendala apa saja yang dihadapi dalam pemberian PB kepada Warga Binaan Pemasyarakatan. Penelitian ini menggunakan sumber data primer dan data sekunder. Data primer didapatkan dari wawancara baik dengan petugas maupun Warga Binaan Pemasyarakatan.

Data sekunder didapatkan dari studi kepustakaan, penelusuran berkas-berkas dokumentasi pada materi perkuliahan dan peraturan perundang-undangan yang memilik keterkaitan. Teknik analisis data dalam penelitian ini menggunakan model interaktif yang di ungkapkan oleh Miles dan Huberman dalam sugiono kegiatan mereduksi data penelitian, penyajian dan penarikan kesimpulan (Sugiyono, 2015).

\section{HASIL DAN PEMBAHASAN}

Dalam menjalani masa pidana WBP wajib melalui tahapan-tahapan dalam proses pemasyarakatan. Unsur-unsur Tindak pidana yang dilakukan dengan dasar pikiran bahwasanya perbuatan dan pertanggung jawaban pidna (kesalahan) merupakan suatu hal yang memiliki keterkaitan yang erat dan sulit untuk dipisahkan (Maramis, 2012).

Dalam proses pemasyarakatan memiliki 4 bagian atau tahapan, yang merupakan satu kesatuan proses (Priyatno, 2016), yakni:

a. Tahap Orientasi/Pengenalan

Setiap narapidana mendapatkan masa pengenalan, pengamatan dan penelitian untuk menjalani masa pidananya di Lapas.

b. Tahap Lanjutan Tahap lanjutan ada 2 bagian, yaitu:

1) Tahap lanjutan pertama, telah dilaksanakannya tahapan awal sampa $1 / 2$ masa pidananya.

2) Tahap lanjutan kedua, tahap lanjutan pertama sampai $2 / 3$ masa pidana. Pembinaan sudah mendapatkan pembinaan kepribadian dan kemandirian, pengawasan medium security.

c. Tahap Integrasi dengan Lingkungan Masyarakat

Tahapan ini merupakan tahapan akhir dari proses pemasyarakatan atau proses pembinaan. Jika telah menjalani tahapan diatas maka WBP berhak diberikan PB atau cuti bersyarat dalam tahap ini proses pembinaan berupa membaurkan WBP dengan masyarakat luas dan pengawasan yang diberikan juga semakin berkurang, lebih menekankan kepada kesadaran diri narapidanya. Masa penahanan yang harus dilewati yaitu $2 / 3$ masa pidananya hingga bebas.

\subsection{Pelaksanaan Pemberian Pembebasan Bersyarat Di Lapas Pemuda Kelas Iia Tangerang}


Pemberian pembebasan bersyarat kepada warga binaan pemasyarakatan di Lapas Pemuda Kelas IIA Tangerang tidaklah diberikan secara langsung atau percuma, melainkan ada syarat dan ketentuan yang harus dipenuhi oleh WBP. pemberian pembebasan bersyarat diatur sesuai dengan Peraturan Pemerintah Nomor 32 Tahun 1999 Tentang Syarat dan Tata Cara Pelaksanaan Hak Warga Binaan Pemasyarakatan, salah satu pemeberian haknya yaitu pembebasan bersyarat. Selanjutnya pembebasan bersyarat diatur lebih lanjut dalam Peraturan Menteri Hukum dan HAM Nomor 03 Tahun 2018 Tentang Syarat dan Tata Cara Pemberian Remisi, Asimilasi, Cuti Mengunjungi Keluarga, Pembebasan Bersyarat, dan Cuti Bersyarat.

Persyaratan substantif yang harus dipenuhi oleh WBP di Lapas Pemuda Kelas IIA Tangerang untuk mendapatkan pemebebasan bersyarat (PB), yakni:

1. Menunjukkan kesadaran diri, penyesalan atas perbuatan sehingga dijatuhi hukuman pidana penjara dan menunjukkan perkembangan perubahan perilaku budi pekerti dan moral yang baik.

2. Mengikuti program pembinaan yang ada dengan baik dan penuh semangat.

3. Berkelakuan baik dalam kurun waktu 6 bulan terakhir, dan Sudah menjalani program pembinaan asimilasi dengan baik.

Selain dari persyaratan substantif ada juga syarat administrasi yang harus diperoleh warga binaan pemasyarakatan agar mendapatkan pembebas bersyarat, meliputi :

1. Eksrak Vonis (Kutipan Putusan Hakim)

2. Laporan penelitian kemasyarakatan yang telah dibuat oleh pembimbing kemasyarakatan dan laporan perkembangan narapidana dalam pembinaan langsung dari kepala Lapas

3. Penyuratan kepada kejaksaan negeri tentang rencana pemberian pembebasan bersyarat bagi warga binaan pemasyarakatan

4. Salinan register F (daftar pelanggaran yang dilakukan oleh warga binaan pemasyarakatan) dari kepala Lapas

5. Salinan perubahan atau perubahan masa pidana dari kepala Lapas.

6. Surat jaminan dari pihak keluarga atau pihak penjamin, yang menyatakan warga binaan pemasyarakatan tidak akan melarikan diri dan akan membantu dalam merubah perilaku warga binaan pemasyarakatan.

7. Surat pernyata warga binaan pemasyarakatan akan selalu berbuat baik dan tidak melanggar hukum lagi.

Untuk warga binaan pemasyarakatan yang terlibat kasus dalam Peraturan Pemerintah Nomor 99 Tahun 2012 tentang perubahan kedua atas Peraturan Pemerintah Nomor 32 Tahun 1999 Tentang Syarat dan tata Cara Pelaksanaan Hak Warga Binaan Pemasyarakatan, akan memberikan penekanan lebih dalam pemberian PB di Lapas Pemuda Kelas IIA Tangerang. Warga binaan pemasyarakatan yang diberikan hukuman pidana penajara karena telah melakukan tindak pidana baik Tindak pidana teroris, narkotika, psikotropika, korupsi, serta kejahatan lainnya yang mengancam keamanan negara dan masyarakat luas yang berakibat pada kejahatan HAM berat. Pembebasan bersyarat bagi WBP yang terikat pada PP Nomor 99 tahun 2012 dapat diberikan apabila warga binaan pemasyarakatan sudah memenuhi syarat, yakni:

1. Berperilaku yang baik; dan Menjalani program pembinaan yang diberikan dengan baik;

2. Tentunya telah menjalani $2 / 3$ masa pidana yang diberikan.

3. Telah mendapatkan Justice Collaborator (bersedia membantu mengungkap kasus)

Selain dari syarat diatas narapidana teroris harus memenuhi syarat lain seperti:

1. Sudah selesai mengikuti program pembinaan deradikalisasi yang dilaksanakan oleh piha Lapas atau 
Badan Nasional Penanggulangan Teroris (BNPT)

2. Telah menyatakan Ikrar

a. Setiap pada NKRI (Negara

Kesatuan Republik Indonesia), secara tertulis. b. Tidak akan mengulangi tindak pidana terorisme bagi warga negara lain, secara tertulis.

Data Usulan PB, CB, dan CMB Tahun 2019 Lapas Pemuda Kelas IIA Tangerang

\begin{tabular}{|c|c|c|c|c|c|}
\hline No & Bulan & $\begin{array}{c}\text { Pembebasan } \\
\text { Bersyarat (PB) }\end{array}$ & Cuti Bersyarat (CB) & $\begin{array}{l}\text { Cuti Menjelang } \\
\text { Bebas (CMB) }\end{array}$ & Jumlah \\
\hline 1 & Januari & 48 & 25 & 3 & 76 \\
\hline 2 & Februari & 7 & 13 & - & 20 \\
\hline 3 & Maret & 6 & 8 & 3 & 17 \\
\hline 4 & April & 45 & 28 & - & 73 \\
\hline 5 & Mei & 35 & 16 & - & 51 \\
\hline 6 & Juni & 7 & 20 & 3 & 30 \\
\hline 7 & Juli & 35 & 23 & 1 & 59 \\
\hline 8 & Agustus & 8 & 14 & - & 22 \\
\hline 9 & September & 80 & 33 & 1 & 114 \\
\hline 10 & Oktober & 30 & 19 & - & 49 \\
\hline 11 & November & 50 & 10 & - & 60 \\
\hline 12 & Desember & 73 & 37 & 4 & 114 \\
\hline & Jumlah Total & 424 & 246 & 15 & 685 \\
\hline
\end{tabular}

Sumber : Dokumen dari Lapas Pemuda Kelas IIA Tangerang.

Melihat dari data tabel diatas petugas pemasyarakatan telah melaksanakan tugasnya dalam hal ini memenuhi hak dari warga binaan pemasyarakatan sehingga mereka dapat segera kembali dengan keluarga, kerabat, teman dan juga masyarakat.

\subsection{Implementasi Pembinaan Wbp Dalam Tahap Pemberian Pembebasan Bersyarat}

Pembebasan Bersyarat (PB) adalah hak dari warga binaan pemasyarakatan yang dimana merupakan kewajiban dari petugas pemasyarakatan untuk memberikan hal tersebut. Mengingat bahwa warga binaan pemasayarakatan merupakan manusia dan harus diperlalukan layaknya manusia pada umumnya, PB yang diberikan merupakan cerminan rasa keadilan yang diberikan dari pihak korban (Madjid et al., 2014).

Pengajuan pembebasayan bersyarat di waktu sekarang sudah banyak perubahan karena sudah menggunakan teknologi (IT) yang dimana pembebasan bersyarat yang dilakukan di Lapas Pemuda Kelas IIA Tangerang sudah berbasis IT.

Alur pengajuan PB di Lapas Pemuda Kelas IIA Tangerang, meliputi:

\section{Unit Pelaksana Teknis (UPT)}

1. Melakukan Pendataan Narapidana dan melengkapi inputan data dan dokumen 
2. Membuat daftar usulan sidang TPP dan melaksanakan sidang TPP

3. Kontrol sidang dan verifikasi sidang

4. Upload surat pengantar selanjutnya kirim/terima data dan dokumen (konsolidasi)

II. Kantor wilayah (KANWIL)

Melakukan verifikasi usulan dalam jangka waktu maksimal 2 hari sejak usulan diterima dari UPT

\section{III.Direktorat}

Jenderal

Pemasyarakatan

Melakukan verifikasi usulan dan membuat persetujuan dan generate SK personal, selanjutnya penandatanganan elektronik Dirjen.

Setelah tahapan diatas telah dilaksanakan maka SK pemberian PB akan ditembuskan kembali ke Kantor wilayah yang meminta dan dicetak sebagai data bahwa telah dilaksanakannya pemberian $\mathrm{PB}$, selanjutnya SK pemberian $\mathrm{PB}$ diteruskan ke UPT lalu dicetak kembali dan diberikan kepada warga binaan pemasyarakatan yang berhak mendapatkan PB.

\subsection{Faktor Penghambat Dalam Pemberian Pb Di Lapas Pemuda Kelas Iia Tangerang}

Berdasarkan hasil penelitian yang dilakukan di Lapas Pemuda Kelas IIA Tangerang, ternyata ditemukan beberapa hambatan atau kendala dalam implementasi pembinaan warga binaan pemasyarakatan dalam hal ini pemberian PB dan upaya yang dilakukan dalam mengatasi masalah-masalah tersebut, yakni:

1) Kelebihan Kapasitas sehingga petugas pemasyarakatan kewalahan dalam menangani pemberian $\mathrm{PB}$.

2) Pengurusan Justice Collaborator (JC) bagi warga binaan pemasyarakatan yang sulit dikarenakan adanya aturan PP Nomor 99 Tahun 2012 Tentang perubahan kedua atas Peraturan Pemerintah Nomor 32 Tahun 1999 Tentang Syarat dan tata Cara
Pelaksanaan Hak Warga Binaan Pemasyarakatan. dalam hal menangani masalah ini maka pihak petugas pemasyarakatan khususnya Lapas Pemuda Kelas IIA Tangerang lebih meningkatkan koordinasi dengan instansi lain yang terkait seperti, kepolisian, kejaksaan, dan pengadilan.

3) Tidak adanya penjamin, untuk mengatasi permasalahan ini seharusnya dapat mempermudah SOP yang bersifat birokratif. Dan batasan mengenai penjamin pun belum diatur syarat dan ketentuannya.

4) Kurangnya anggaran pembinaan Warga Binaan Pemasyarakatan dan juga sarana dan prasarana dalam sehingga tidak dapat memenuhi program pembinaan.

Kendala-kendala yang dihadapi petugas lainnya seperti (Riana et al., 2013):

1) Kendala kepegawaian

Kurangnya tenaga SDM petugas yang profesional dibidangnya seperti dibidang pelatihan dan pengajaran untuk warga binaan pemasyarakatan.

2) Kendala Kultur dan masyarakat

Stigmanisasi yang dilakukan oleh masyrakat, sehingga selah-olah kurang mendukung dalam keberhasilan pembinaan di Lapas. dan kurangnya sosialisasi dari lembaga pemasyarakatan mengenai tugas dan fungsi serta peran bagi masyarakat.

3) Kendala ekonomi warga binaan pemasyarakatan

Setelah mendapatkan PB, warga binaan pemasyarakatan masih dalam pengawasan Bapas dengan kata lain mereka harus lapor setiap 1 kali seminggu ke Bapas sehingga mereka berfikiran akan banyak biaya yang keluar. Sedangkan bagi warga binaan pemasyarakatan yang tidak mampu itu akan terasa sulit dan akan memilih untuk tidak mengambil haknya tersebut.

\section{KESIMPULAN}

Program Pembebasan bersyarat dalam kegiatan pembinaan bagi warga 
binaan pemasyarakatan di Lapas Pemuda Kelas IIA Tangerang telah dilaksanakan sesuai dengan aturan hukum dan standar operasional yang berlaku, seperti :

1. Program pembinaan pemberian $\mathrm{PB}$ merupakan tahap Integrasi agar warga binaan pemasyarakatan dapat berbaur kembali ke lingkungan masyarakat tanpa adanya penolakan.

2. Program pembinaan pemberian $P B$ di berikan dengan melalui tahapantahapan mulai dari masa penahanan hingga program pemberian $\mathrm{PB}$, dalam pemberian tersebut petugas akan selalu mengamati dan membina warga binaan pemasyarakatan menjadi lebih baik dari sebelum dia masuk penjara.

Selain itu, pembinaan pemberian PB di Lapas Pemuda Kelas IIA tangerang tentu saja dalam pelaksanaannya ada beberapa permasalahan atau kendala yang dihadapi petugas pemasyarakatan maupun warga binaan pemasyarakatan, yakni:

1. Kendala atau hambatan yang dihadapi dalam pelaksanaan pemberian $\mathrm{PB}$ yaitu tidak adanya penjamin bagi syarat administrasi pengusulan PB bagi warga binaan Pemasyarakatan.

2. Kondisi Lapas yang sekarang sudah melebihi kapasitas sehingga pelaksanaan program pembinaan pemberian $\mathrm{PB}$ tidak berjalan dengan baik,

3. Warga binaan pemasyarakatan yang memiliki ekonomi rendah dalam pelaksanaan kurang semangat,

4. Pihak penjamin yang tidak sesuai sehingga nantinya yang ditakutkan tidak adanya penanggung jawab untuk pengawasan warga binaan pemasyarakatan,

5. Pengajuan Justice Collaborator sangat susah, dan anggaran untuk Lembaga Pemasyarakatan sangatlah kurang sehingga pembinaan tidak berjalan secara maksimal.

Selama menjalani masa pidana atau kehilangan kebebasan bergerak, warga binaan pemasyarakatan (WBP) harus diperlakukan secara manusiawi dan tidak boleh dijauhkan dari kehidupan masyarakat. Pembebasan bersyarat di berikan guna untuk membaurkan warga binaan pemasyarakatan di lingkungan masyarakat, menghilangkan stigma masyarakat terkait bekas WBP (narapidana), merubah sikap dan perilaku WBP menjadi lebih sopan dan santun. Dalam program yang diberikan harus mencipatakan rasa nyaman bagi WBP dan dilakukan secara berkesinambungan, tidak menimbulkan dendam bagi warga binaan pemasyarakatan, petugas, dan masyarakat. Dalam pembinaan harus ada Reward and Punishment, penghargaan dan penghukuman harus disampaikan kepada warga binaan pemasyarakatan agar mereka memahami tugas akan hak dan kewajiban yang akan dilakukan dalam menjalani masa pidananya.

\section{DAFTAR PUSTAKA}

Cresswell, J. W. (2016). Research Design. Pustaka Pelajar.

Kuhp. (2013). Madjid, M., Pidana, B. H., Hukum, F., \& Hasanuddin, U. (2014). Pelaksanaan Pemberian Hak Narapidana Mendaoatkan Pembebasan Bersyarat (Studi Kasus Di Rutan Kelas Iib Masamba). 47.

Maramis, F. (2012). Hukum Pidana Umum Dan Tertulis Di Indonesia. Ptrajagrafindo Persada.

Priyatno, D. (2016). Sistem Pelaksanaan Pidana Penjara Di Indonesia. $\mathrm{Pt}$ Refika Aditama.

Riana, A., Aji, A., \& Sari, N. P. (2013). Kendala Pemberian Pembebasan Bersyarat Di Lembaga Pemasyarakatan Kelas Iia Sragen. 2(3), 287-288.

Rukmana, D. A. (2015). Tinjauan Yuridis Terhadap Pembebasan Bersyarat Narapidana Tindak Pidana Korupsi. 22.

Sugiyono. (2015). Memahami Penelitian Kualitatif. Alfabeta.

Uu Nomor 12 Tahun 1995. (N.D.). 